\title{
ALTERAÇÕES SOCIOAMBIENTAIS E NA SAÚDE DECORRENTES DA IMPLANTAÇÃO DE PROJETOS DE MINERAÇÃO EM BARCARENA- PA: O DESENVOLVIMENTO E SUAS CONTRADIÇÕES NA AMAZÔNIA, BRASIL
}

\section{ARTIGO ORIGINAL}

SOUZA, Keulle Oliveira da ${ }^{1}$

MOREIRA, Elisângela Claudia de Medeiros ${ }^{2}$

DIAS, Cláudio Gellis de Mattos ${ }^{3}$

FECURY, Amanda Alves ${ }^{4}$

NETO, Manoel Samuel da Cruz ${ }^{5}$

\footnotetext{
${ }^{1}$ Mestranda em Estudos Antrópicos na Amazônia-PPGEAA, na Universidade Federal do Pará - UFPA, Campus Castanhal.

${ }^{2}$ Mestre em Teoria e Pesquisa do Comportamento. Docente da Universidade do Estado do Pará - UEPA, Belém (PA). Doutoranda em Doenças Tropicais na Universidade Federal do Pará - NMT/UFPA.

${ }^{3}$ Doutor em Teoria e Pesquisa do Comportamento. Docente e Pesquisador do Instituto Federal do Amapá - IFAP.

${ }^{4}$ Doutora em Doenças Tropicais. Docente e Pesquisadora da Universidade Federal do Amapá, AP. Pesquisadora colaboradora do Núcleo de Medicina Tropical da UFPA (NMT-UFPA).

${ }^{5}$ Mestre em Enfermagem. Docente e Pesquisador na Faculdade Brasil Amazônia FIBRA.
} 
DENDASCK, Carla Viana ${ }^{6}$

PIRES, Yomara Pinheiro ${ }^{7}$

BAHIA, Mirleide Chaar ${ }^{8}$

FERNANDES, Roseane do Socorro da Silva Matos ${ }^{9}$

OLIVEIRA, Euzébio de ${ }^{10}$

SOUZA, Keulle Oliveira da. Et al. Alterações socioambientais e na saúde decorrentes da implantação de projetos de mineração em Barcarena-PA: 0 desenvolvimento e suas contradições na Amazônia, Brasil. Revista Científica Multidisciplinar Núcleo do Conhecimento. Ano 04, Ed. 12, Vol. 08, pp. 29-39. Dezembro de 2019. ISSN: 2448-0959, Link de acesso: https://www.nucleodoconhecimento.com.br/meio-ambiente/alteracoessocioambientais

${ }^{6}$ Teóloga. Doutora em Psicanálise Clinica. Pesquisadora do Centro de Pesquisa e Estudos Avançados, São Paulo, SP.

${ }^{7}$ Doutora em Engenharia Elétrica. Docente e Pesquisadora na Universidade Federal do Pará - UFPA, Campus Castanhal.

${ }^{8}$ Doutora em Ciência: Desenvolvimento Socioambiental. Docente e Pesquisadora do Núcleo de Autos Estudos Amazônicos da Universidade Federal do Pará NAEA/UFPA.

${ }^{9}$ Doutora em Educação. Docente e Pesquisadora no Instituto de Ciências da Saúde da Universidade Federal do Pará - ICS/UFPA.

${ }^{10}$ Doutor em Medicina/Doenças Tropicais. Docente e Pesquisador na Universidade Federal do Pará - UFPA. Pesquisador Colaborador do Núcleo de Medicina Tropical NMT/UFPA, Belém (PA), Brasil. 


\section{RESUMO}

Diante de questões ambientais e a atividade de extração de minérios, é importante analisar, a relação entre as questões socioambientais e de saúde e as atividades de mineração e suas relações diretas com o desenvolvimento, sobretudo o econômico. O presente trabalho objetivou avaliar as alterações socioambientais e na saúde decorrentes da implantação dos grandes projetos de mineração em Barcarena-PA, contextualizando o desenvolvimento e suas contradições na Amazônia brasileira. Para tanto, utilizou-se de pesquisa bibliográfica, acerca da literatura publicada em livros, artigos científicos e documental, relativa ao tema em estudo. Constatou-se que o Brasil representa um dos maiores potenciais de recursos minerais do planeta, com aproximadamente 55 tipos de minerais que podem ser aproveitados para fins de exploração econômica. Por outro lado, além de contribuir para o fortalecimento da economia regional e nacional e para a geração de empregos e o aumento da renda da população local, como é o caso do município de Barcarena-PA, essa região tem sofrido consecutivos impactos socioambientais e na saúde, em decorrência das atividades mineradoras desenvolvidas na região. O entorno dos grandes projetos de mineração é habitado por famílias que, desde a sua implantação possuem o seu modo de vida, sua economia, sua saúde e sua organização sociocultural impactados, decorrentes dessa atividade e dos sucessivos impactos ambientais que ocorrem no local. Diante de tudo o que foi analisado, é possível concluir que, por ser um modelo de desenvolvimento econômico acelerado, e por muitas vezes não planejado corretamente, não levando em consideração as peculiaridades da Amazônia brasileira, acaba por gerar inúmeros impactos ambientais, sociais que inclusive refletem diretamente em sérios agravos na saúde da população local. Tornando-se assim indispensável repensar urgentemente essa forma de implantação dos projetos de exploração mineral na região amazônica, como é o caso da cidade de Barcarena, pois grandes desastres socioambientais ainda podem ocorrer.

Palavras-chaves: Alterações, socioambientais, saúde, mineração, Amazônia. 


\section{INTRODUÇÃO}

Os minérios existem desde o princípio do mundo. Eles são formações minerais que se compõem naturalmente e são economicamente interessantes para a sua extração. $\mathrm{Na}$ Terra, o ferro é quem aparece em maior abundância de produção na crosta. $\mathrm{Na}$ lista de minérios de grande relevância para nossas vidas, temos, ainda, o cobre, ouro, alumínio e carvão mineral. A lista é imensa, e eles são essenciais para o modelo de desenvolvimento implantado no globo terrestre. Sem eles nada seria a mesma coisa como vemos hoje. E cada vez mais serão necessários, pois quanto maior for o desenvolvimento tecnológico, maior será a demanda por esses produtos (OLIVEIRA, 2019; SIMINERAI, 2019).

O Brasil representa um dos maiores potenciais de recursos minerais do planeta, com aproximadamente 55 tipos de minerais que podem ser aproveitados para fins de exploração, como ferro, cobre, ouro, manganês, nióbio, entre outros. As reservas brasileiras de ferro apresentam um teor médio de $45,7 \%$, e representam $17 \%$ das reservas mundiais. No Estado do Pará, Norte do Brasil, "a indústria mineral gera 266 mil empregos diretos e indiretos na cadeia produtiva local e responde por $20 \%$ do Produto Interno Bruto paraense" (SIMINERAI, 2019).

Como se sabe, essas indústrias implantam na região, gigantescas obras e estruturas, tais como essa Refinaria (Figura 1), instalada na cidade de Barcarena-PA, para o refino dos minerais extraídos dos solos amazônicos. 
Figura 1: Refinaria de minerais extraídos, Barcarena-PA. Fonte: Tarso Sarraf, O LIBERAI, 2017.

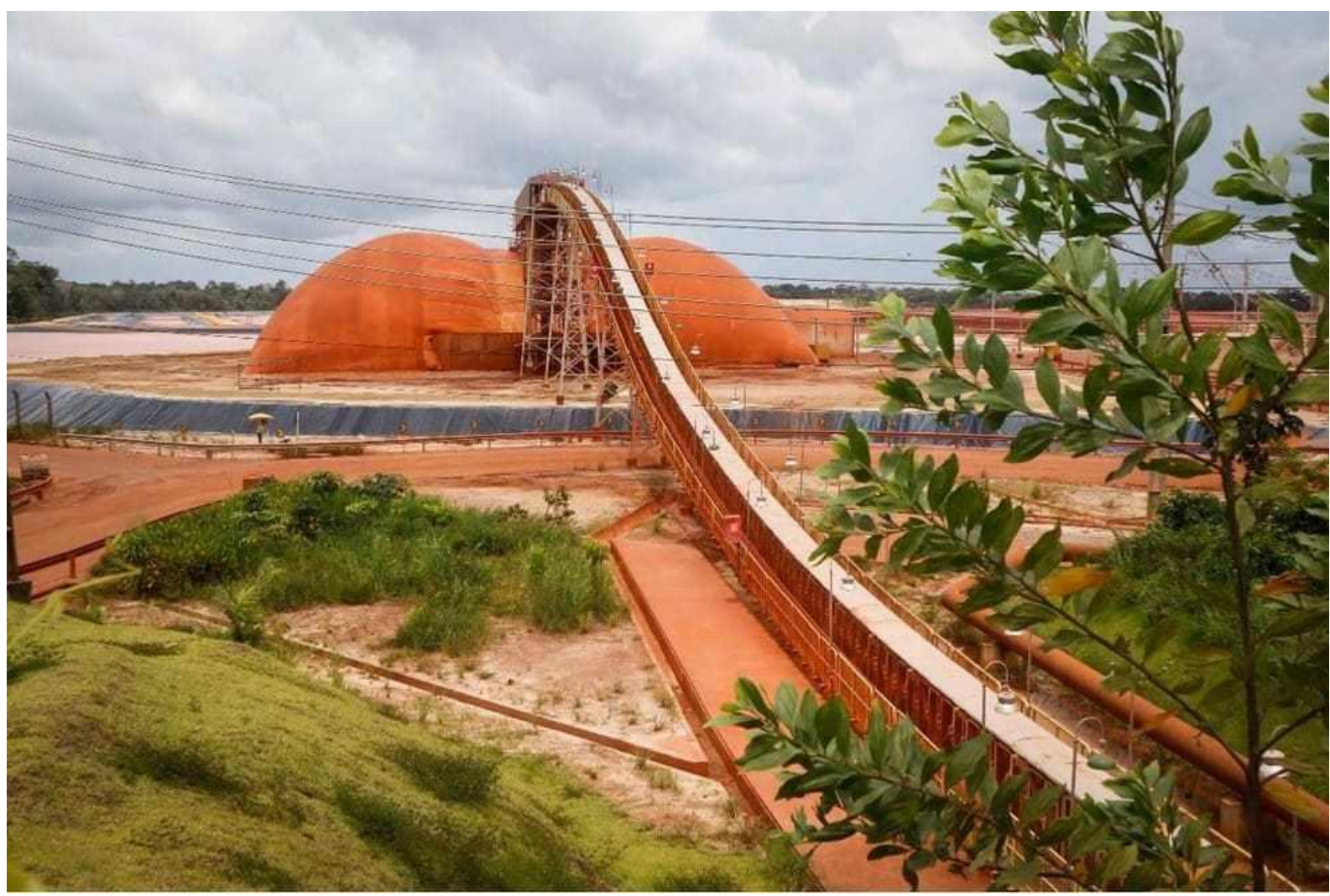

Fonte: Dados da Pesquisa.

Por outro lado, além de contribuir para o fortalecimento da economia regional e nacional e para a geração de empregos e o aumento da renda da população local, o município de Barcarena-Pa, tem sofrido consecutivos impactos socioambientais e na saúde, em decorrência das atividades mineradoras desenvolvidas na região. $O$ entorno dos grandes projetos de mineração é habitado por famílias que, desde a sua implantação possuem o seu modo de vida, sua economia, sua saúde e sua organização sociocultural impactados diretamente com os inúmeros desastres socioambientais ocorridos no local (NASCIMENTO; HAZEU, 2015).

Nos últimos vinte anos foram registrados vazamentos de bauxita, caulim, contaminação de rios, igarapés e poços de água, que abastecem as famílias, afetando

Disponível em: https://www.nucleodoconhecimento.com.br/meio-ambiente/alteracoes- 
diretamente a vida das comunidades locais, causando danos incalculáveis para a saúde dos moradores e para o meio ambiente em que vivem (MAIA; MARIN, 2014).

A magnitude e a complexidade de compreender o fenômeno torna indispensável buscar referências na área das Ciências Sociais e da Saúde, tendo em vista que o meio ambiente e a saúde são campos indissociáveis do ser humano, relacionados diretamente com a sua existência e permanência na Terra. Entretanto, o meio ambiente em sua alta complexidade não necessita do ser humano para permanecer e existir. Neste entremeio, "as reflexões são pautadas, a fim de compreender de que maneira o meio ambiente interfere na saúde humana e como o ser humano interfere no equilíbrio do meio ambiente", ou seja, é de suma importância conhecer as causas, as inferências e os impactos, provocados pelo ser humano no meio ambiente (MACEDO, 2019, p. 20).

Diante do exposto torna-se necessária uma compreensão mais ampla, sobre as alterações ou impactos socioambientais e na saúde dos moradores locais, decorrentes da implantação dos projetos de mineração em Barcarena- $\mathrm{Pa}$, visando compreender como ocorreram e ainda ocorrem esses processos de instalação e funcionamento desses grandes empreendimentos, para assim caracterizar os possíveis prejuízos no ambiente e na saúde dos moradores do local e proximidades.

Sendo assim, o presente trabalho objetivou avaliar as alterações socioambientais e na saúde decorrentes da implantação dos grandes projetos de mineração em Barcarena-PA, contextualizando o desenvolvimento e suas contradições na Amazônia brasileira, decorrente desses empreendimentos.

\section{METODOLOGIA}

O presente trabalho foi realizado por meio de um estudo descritivo-analítico e exploratório, desenvolvido por meio de pesquisa bibliográfica acerca da literatura publicada em livros, artigos científicos e documental, relativa ao tema em estudo. Quanto à abordagem, é qualitativa, buscando analisar a realidade do tema destacando-se os principais autores que discutem os grandes projetos na região 
amazônica brasileira, sobretudo em Barcarena-PA, município limítrofe com Belém, Ponta de Pedras e Abaetetuba, todos pertencentes ao Estado do Pará.

É de caráter descritivo-analítico, posto que buscou classificar, descrever, explicar e esclarecer o problema apresentado. É, também, exploratória, pois objetivou pesquisar, analisar e descrever as ideias principais dos autores, através das informações pesquisadas sobre o tema em foco.

\section{RESULTADOS E DISCUSSÃO}

A instalação de grandes projetos de mineração na região da Amazônia brasileira, tem sustentado muitas discussões ao longo do tempo. No início do século XX a instalação do empreendimento de Henry Ford, a conhecida Ford Motor Company, representou a chegada das empresas modernas no Estado do Pará, gerando grandes expectativas para o começo do desenvolvimento industrial e econômico para a região. A instalação desse grande projeto desenvolvimentista, deu origem a cidade de Belterra e a Vila, popularmente conhecida como Fordlândia, representando também o modelo de exploração, baseado na extração da borracha, para o atendimento da demanda automobilística internacional (CANTO, 2015).

De modo mais amplo, e por consequência da instalação dos grandes projetos industriais na região, os conflitos socioambientais existentes hoje na Amazônia brasileira, constituem-se como processos complexos, que envolvem diversos sujeitos e múltiplos interesses, desde os econômicos até os de preservação ambiental. Para Canto (2016, p. 89), "A territorialização das grandes empresas, estrangeiras ou não, tem sido o epicentro de conflitos socioambientais nos mais variados rincões da Amazônia". Tensões das mais diversas origens, que envolvem extração mineral, explorações madeireiras, questões fluviais, conflitos agrícolas e pastoris, conflitos pesqueiros, demarcação de terras indígenas e tantos outros.

No contexto da exploração mineral, partir da década de 70 as instalações de grandes empreendimentos ganharam força no Estado do Pará. Como desdobramento do Projeto Grande Carajás (PGC), implantou-se na região empresas voltadas à produção 
de alumina e alumínio primário. A empresa brasileira Albrás instalou-se no município paraense de Barcarena, iniciando sua operação em 1985 (MONTEIRO, 2005; MACÊDO, 2019).

Barcarena foi a cidade escolhida para sediar grandes projetos industriais, devido a sua posição estratégica para atender aos mercados europeus e norte-americanos, primeiramente: pela disponibilidade de mão de obra barata, altamente necessárias para alguns postos de emprego e pela sua proximidade à capital do Estado do Pará, a cidade de Belém, facilitando assim as atividades da empresa (NAHUM, 2011; SILVA, HAZEU, 2019). (Figura 2).

Figura 2: Localização do município de Barcarena-PA.

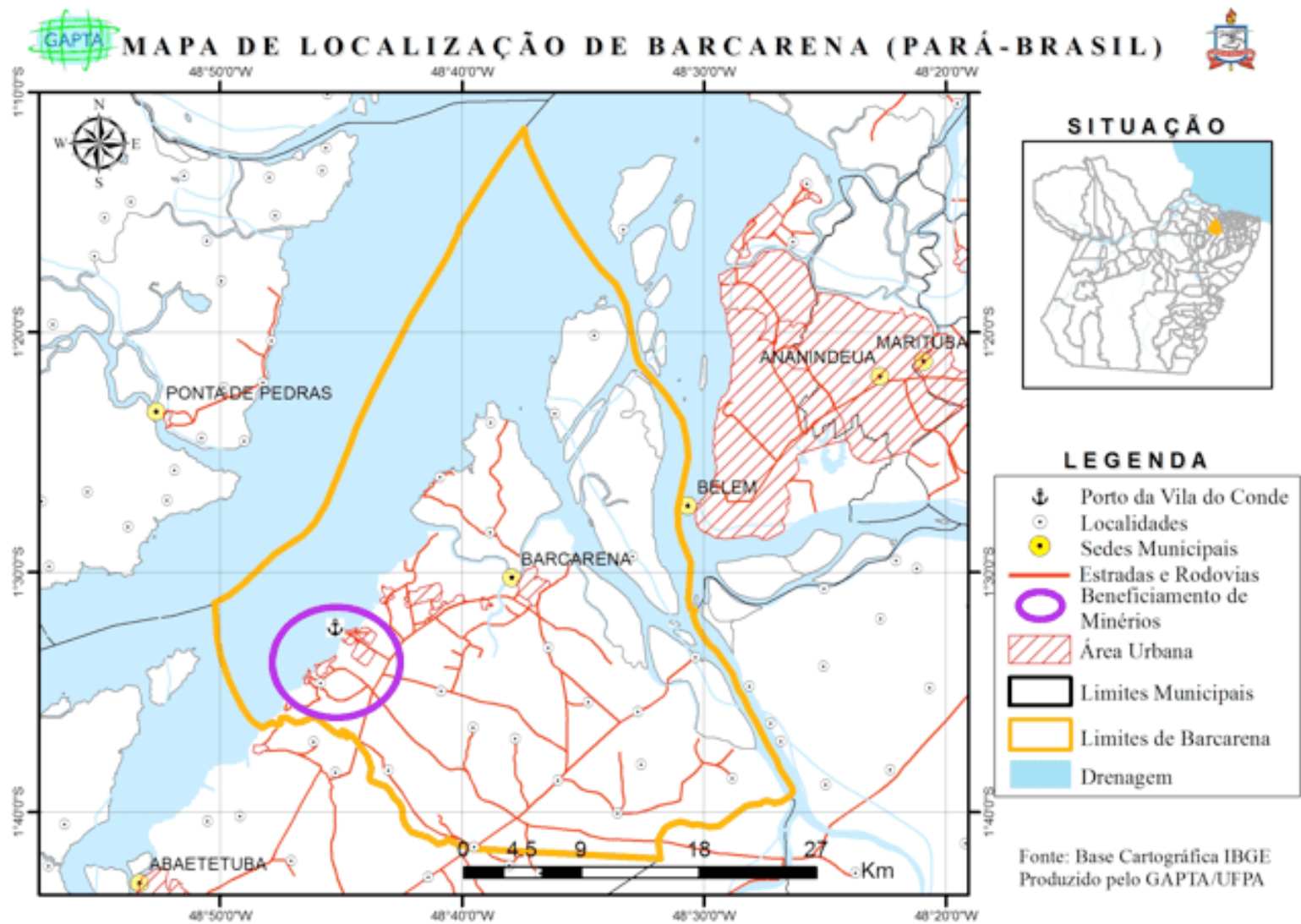

Fonte: Base Cartográfica do IBGE- Produzido pelo GAPTA/UFPA, 2017.

A implantação dos grandes projetos industriais desenvolvimentistas em Barcarena foi entrelaçada por uma série de processos de deslocamentos, na maioria das vezes $\mathrm{RC}: 42705$

Disponível em: https://www.nucleodoconhecimento.com.br/meio-ambiente/alteracoessocioambientais 
contra gosto, de comunidades tradicionais que viviam na região. Marin (2017), destaca que há uma evidente tensão entre, as territorialidades específicas que compunham o município antes da década de 1970, e os grandes empreendimentos ali instalados, devido a imposição de uma forma de desenvolvimento acelerado, em grande parte não bem planejados, que foi tomada pela visão industrial, sobretudo a partir de 1980.

A formulação de políticas estatais capazes de abarcar os grandes projetos, e ao mesmo tempo mediassem a relação com as populações tradicionais de Barcarena foi fundamental e estratégica, em um contexto marcado pelo convencimento da população local, pela ideia do progresso para o município. Para (CARMO; COSTA, 2016, p. 291) "na década de 1980, as atenções das políticas públicas se voltaram para o município, para que ele atendesse aos interesses do Estado e aos interesses externos", recebendo um grande projeto denominado de Complexo Industrial da Alunorte.

Segundo Maia e Marin (2018), as empresas Norsk Hydro (Alunorte e Albrás), a Imerys Rio Capim Caulim, a Pará Pigmentos, a Buritama, a Tecop, a Votorantin e a Usipar transformam continuadamente o município de Barcarena, transformando a região em um depósito de rejeitos industriais, desmatando florestas e deslocando pessoas e comunidades inteiras, para construir mais bacias de rejeitos, impactando a vida dessas comunidades tradicionais, gerando com isso sérios danos ao meio ambiente, agravando as questões sociais e gerando, consequentemente grandes agravos à saúde dessas populações.

Dentre os minerais mais explorados na região de Barcarena, pode-se destacar o alumínio (AL), que é alvo de críticas por uma boa parte dos médicos. Os mesmos afirmam que a intoxicação por alumínio Al tem sido cada vez mais estudada e está associada à constipação intestinal, cólicas abdominais, anorexia, náuseas, fadiga, alterações do metabolismo do cálcio (raquitismo), alterações neurológicas com graves danos ao tecido cerebral. Na infância pode causar hiperatividade e distúrbios do aprendizado. Inúmeros estudos consideram que o $\mathrm{Al}$ tem um papel extremamente importante no agravamento do mal de Alzheimer (demência precoce). O excesso de 
Al interfere com a absorção do selênio e do fósforo. Os alimentos ácidos aumentam a absorção do Al e aumentam a liberação do mesmo das panelas fabricadas com este mineral (PRADO FILHO, 2010).

De acordo com Salvador (2013), é necessário e urgente uma ação enérgica de nossas autoridades, quer para assegurar à população da região, incluindo os próprios trabalhadores exames laboratoriais completos e transparentes, sem maquinações, para se diagnosticar os adoecimentos decorrentes da contaminação pelos materiais pesados danosos à saúde humana, utilizados na exploração da cadeia do alumínio, preservando-se a saúde pública desses cidadãos.

Todo trabalhador doente, ainda com sequelas e ou incapacitação para o trabalho, deve ter garantido o seu direito à exames de diagnósticos sérios e verdadeiros, objetivando o recebimento do auxílio da previdência, garantido por lei para todo trabalhador com sequelas e ou incapacidades profissionais, que em muitos casos tem sido negado, quer pelas práticas falhas das notificações, ou pela prática realizada pelo INSS de redução de seus custos com a concessão de auxílios previdenciários, ao invés de se fazer as fiscalizações moralizadoras para que a legislação protetiva do trabalho humano, com segurança, saúde e dignidade se cumpra, sem os conhecidos vícios do sistema (SALVADOR, 2013).

\section{CONSIDERAÇÕES FINAIS}

Nesta lógica contraditória de desenvolvimento, observa-se que a disputa mundial pelos recursos naturais da região amazônica brasileira faz com que a disputa pelo controle do seu território, torne-se crucial no contexto geopolítico da Amazônia. No entanto, este modelo contrasta fortemente com a dinâmica populacional, econômica, cultural, política e social da região.

E por ser um modelo de desenvolvimento econômico acelerado, e por muitas vezes não planejado corretamente, levando em consideração as peculiaridades da Amazônia brasileira, acaba por gerar inúmeros impactos ambientais, sociais que 
inclusive refletem diretamente em sérios agravos na saúde da população local, como constatado nesta revisão.

Por tudo o que foi analisado, torna-se assim necessário repensar urgentemente essa forma de implantação dos projetos de exploração mineral na região amazônica do Brasil, pois grandes desastres socioambientais ainda podem ocorrer, acometendo muitas vidas humanas.

\section{REFERÊNCIAS}

CANTO, O. Mineração na Amazônia: assimetria, território e conflito socioambiental. NUMA, UFPA. 2016.

CARMO, M.; COSTA, S. Os paradoxos entre os urbanos no município de Barcarena, Pará. Disponível em: https://periodicos.pucpr.br/index.php/Urbe/article/view/22077/21187. Acesso em 07 de Outubro de 2019.

MACEDO, J. Desastre Socioambiental em Barcarena: a percepção dos moradores de Vila do Conde sobre o naufrágio Haidar. Dissertação de mestrado. Programa de Pós-Graduação em Estudos Antrópicos na Amazônia. UFPA/Castanhal. 126 folhas. 2019.

MAIA, R. Territorialidades específicas em Barcarena confrontadas com projetos de "desenvolvimento". 2017. 321 f. Tese (Doutorado) - Universidade Federal do Pará, Programa de Pós-Graduação em Desenvolvimento Sustentável do Trópico Úmido. Núcleo de Altos Estudos Amazônicos, Belém, 2017.

MAIA, R.; MARIN, R. A arte da resistência de comunidades tradicionais em Barcarena (Pará) face à ordem e progresso. Papers do 38 Encontro da ANPOCS, GT07 Conflitos ambientais, Estado e ideologia do desenvolvimento: mediação e luta por direitos. Minas gerais, out. 2014. 
MAIA, R.; MARIN, R. Gênero nas ações e resistências ao modelo de desenvolvimento imposto em Barcarena, Pará. Cad. Pagu. n.52, Nov. 2018. ISSN 0104-8333. Dossiê Desenvolvimento, Poder, Gênero e Feminismo.

MONTEIRO, M. A. Meio século de mineração industrial na Amazônia e suas implicações para o desenvolvimento regional. Coleção Estudos Avançados, Ed. 19 (53), 2005.

NASCIMENTO, N. S. F.; HAZEU, M. T. Grandes empreendimentos e contradições sociais na amazônia: a degradação da vidano município de Barcarena, Pará. Argumentum, Vitória (ES), v. 7, n. 2, p. 288-301, jul/dez. 2015.

NAHUM, J. S. USOS LOCAIS DAS NORMAS GLOBAIS: implantação da lei de responsabilidade fiscal em Barcarena-Pará (local uses of the global norms: the implantation of the law of fiscal responsibility in Barcarena-Pará). Mercator, Fortaleza, v. 7 , n. 13 , p. p. 7 a 18 , nov. 2008. ISSN 1984-2201.

NAHUM, J. S. Usos Locais das Normas Globais: implantação da Lei de Responsabilidade Fiscal em Barcarena. Mercator. Revista de Geografia da UFC. v. 07, p. $7-18,2008^{\text {a }}$.

OLIVEIRA, B. A. A riqueza debaixo dos nossos olhos: o potencial mineral no Amazonas. Opinião Editorial Open Weather, 04, junho, 2019.

PRADO FILHO, H, R, D. A insustentabilidade da indústria do alumínio. Qualidade online. 16, novembro, 2010.

SALVADOR, L. RISCOS À SAÚDE PÚBLICA: Da gigantesca degradação ambiental produzida pela exploração da cadeia do alumínio. Asociacion Latino Americana de Abogados Laboralistas (ALAL). 28, julho, 2013.

SILVA, S.; HAZEL, M. O Complexo Industrial-portuário em Barcarena e a Saúde de Comunidades Tradicionais na Amazônia Brasileira. O Social em Questão - Ano XXII - no 44 - Mai a Ago/2019. 
SIMINERAL. Sindicato das Indústrias Minerais do Estado do Pará, 2019.

Enviado: Dezembro, 2019.

Aprovado: Dezembro, 2019. 